\section{Expect the unexpected: the vital need for wild plants in a Bronze Age farmer's diet}

\author{
Yvonne van Amerongen ${ }^{1,2}$ \\ ${ }^{1}$ Faculty of Archaeology, Leiden \\ University, Leiden; ' ${ }^{2}$ ARTH Integrated \\ Archaeology, Amersfoort, The \\ Netherlands
}

\section{Abstract}

Wild plant gathering and consumption has previously been described as being unimportant during the Bronze Age in the western Netherlands. It was believed that the people were full-time farmers and that the food produced on the settlement was enough for people to be self-sufficient. However, the analysis performed here to re-evaluate this statement has shown that wild plants were also essential to life in the Bronze Age. The combined information obtained from ethnography, ethnobotany, archaeology, ecology, nutritional studies, and physical anthropology has indeed indicated that wild plants, and especially their vegetative parts, would have had to have been gathered yearround in order for people to remain healthy.

\section{Introduction}

The Bronze Age in the western Netherlands (ca. 2000-800 BC) is characterised by permanent settlements and the practice of mixed farming. Crops and domestic animals were produced by these settlements and people were seemingly self-reliant, overthrowing the need for wild resource exploitation. Some would even go as far as to define these farmers as living with their backs towards nature and suggest that edible wild plants (were) practically abandoned during the Bronze Age (Louwe Kooijmans, 1993; Brinkkemper, 2013). However, one of the areas in the (north-)western Netherlands, West Frisia, has yielded large amounts of botanical remains, also from wild plant species. Therefore, the available data from West Frisia was utilised to re-evaluate the previously mentioned statements and to re-assess the importance of wild plant gathering for Bronze Age subsistence. The disciplines employed in this re-evaluation include ethnography, ethnobotany, archaeology, ecology, nutritional studies, and physical anthropology. This interdisciplinary approach has provided concrete evidence that wild plants still formed an essential part of the Bronze Age diet, and its subsistence at large.

\section{Materials and Methods}

In this study, the need for wild plant exploitation in the Bronze Age is based on evidence from several disciplines. The information obtained from these disciplines is used as a comparison with the data from West Frisia, The Netherlands. Each of the applied disciplines will be briefly discussed below.

\section{Ethnography}

The ethnographical work by Murdock (1981) was employed here to create a general idea of the importance of wild plant gathering in the subsistence of mixed (i.e., crop and animal husbandry) farmers. A selection was made from the available culture groups researched by Murdock, so that only the cultures remained that presumably most closely resemble the Dutch Bronze Age situation. The selection criteria were: more than $50 \%$ of the food economy needed to consist of crop and animal husbandry (i.e., full-time farmers); the type of agriculture needed to be intensive agriculture on permanent fields with short fallow; crops needed to consist of cereals; settlement size needed to be relatively small, consisting of homesteads, hamlets, or compact settlements; and animal husbandry needed to be focused on bovine animals. It is worth noticing that the work of Murdock only reviews the food economy part of subsistence.

\section{Ethnobotany}

Several ethnobotanical studies were consulted to investigate the range of wild plant species used by European (farming) communities (Ertug, 2000, 2004; Łuczaj, 2010, 2012; Kalle and Sõukand, 2012). Also, an online ethnobotanical database (PFAF 2015) was consulted to evaluate the edibility of the West Frisian wild plants, as well as the part of the plant used for consumption.

\section{Archaeology}

Some archaeological indications for prehistoric wild plant collecting and consumption were listed by Behre (2008). This information is mainly based on the presence of wild plant seeds in the stomach of bog bodies and as pure concentrations on excavated settlement sites.

\section{Ecology}

The ecological groups to which the found plant species belong were based on the work of Tamis et al. (2004). These groups were applied to the plant species in order to identify if a plant species could have grown strictly locally or whether it was more likely that the assemblage was the result of intentional gathering from the further surroundings.
Correspondence: Yvonne F. van Amerongen, EARTH Integrated Archaeology, Basicweg 19, 3821BR Amersfoort, The Netherlands.

Tel: +31.033.4554127.

E-mail: y.van.amerongen@earth-arch.eu

Key words: Vegetative wild plants; Diet; Health; Taphonomy; Bronze Age.

Conflict of interest: the author declares no potential conflict of interest.

Funding: this research was funded by the Netherlands Organisation for Scientific Research (NW0).

Acknowledgements: thanks to Helen 0'BrienMáčel for checking and correcting the text as a native speaker.

Conference presentation: this paper was presented at the International Open Workshop 2015 of the Graduate School Human Development in Landscapes of Kiel University, and forms a part of the Book of Abstracts of the session Method development to reveal past plant-people interactions.

This work is licensed under a Creative Commons Attribution 4.0 License (by-nc 4.0).

(c) Copyright Y. van Amerongen 2016

Licensee PAGEPress, Italy

Open Journal of Archaeometry 2016; 3:6284

doi:10.4081/arc.2016.6284

\section{Nutritional studies}

Information on present-day human nutrition requirements was obtained from a World Health Organisation/Food and Agriculture Organisation of the United Nations report (WHO/FAO, 2002). In this report, the most critical micronutrients were listed for people with a staple diet consisting of cereal grains. The essential micronutrient requirements in this report were used as a guideline to calculate the adequacy of a farmer's diet in relation to wellbeing with and without the presence of wild plants. The farmer's diet without wild plants was assumed to consist of cereal grain, beef, and milk (WHO/FAO, 2002; Piironen et al., 2008; Chatzav et al., 2010; Raw milk, 2015; USDA, 2015).

\section{Physical anthropology}

Reports on north-western European human skeletal remains dated to the Bronze Age provided indications for general health as well as specific indications for nutritional deficiencies (Bennike, 1985; Smits and Maat, 1993; Hermanussen and Kühl, 2006; Mays, 2008; Mount, 2012; Tornberg, 2013; Veselka, 2015). 


\section{Results and Discussion}

\section{Plant gathering in farming commu- nities}

The combination of ethnographical, archaeological, and ethnobotanical studies has given indications for the use of wild plants in present-day and prehistoric communities. Ethnography has provided general information on the consumption of wild plants as an addition to the diet, and archaeology has provided the general information on the consumption of specific wild plant species preserved in bog bodies and soils. The ethnobotanical studies on farming communities from Poland, Slovakia, Estonia, and Turkey have provided an even more detailed view on wild plant use. In these studies, all the uses of specific wild plant species are recorded. For example, from the study of Ertug (2004) it has become clear that $44 \%$ of all collected wild plants in Turkey are collected for consumption, and that most of these are collected for their vegetative parts (Ertug, 2000, 2004). The other countries differ in their preferences for collecting specific wild plant parts, but the general consumption of wild plants remains important for subsistence.

\section{Edible wild plants in West Frisia}

The plant species from West Frisia normally termed weeds were evaluated on edibility and plant part used for consumption with the aid of the online ethnobotanical database (PFAF, 2015). Only charred seeds/fruits from ditches around houses (these ditches are dry gullies dug around the houses, in which household waste has accumulated) were used for this analysis, because this particular preservation state and context most accurately signify the probability of human use. This means that the results shown here represent a tip of the iceberg of the potentially much larger taxa list of plants used by Bronze Age people when also uncharred remains are considered (van Amerongen, in press). The information obtained from the different disciplines mentioned above was applied to and compared with the West Frisia data. Also, the ecological growing locations of the plant species were translated into groups representing the growing location in relation to the house (e.g. local or off-site). Within such a group, plant species that belonged to the same genus and had similar edibility and edible part characteristics were combined. This combination was made because the ethnobotanical studies show that plant species from the same genus, with similar appearance, taste, and edible parts, are often collected together and can even have the same local name (Ertug, 2000, 2004; Łuczaj, 2010, 2012; Kalle and Sõukand, 2012).

A wide variety of wild edible plant species is represented in the West Frisian data, originating from a wide variety of ecological locations (Table 1). A recent study on wild plant use in present-day Europe indicates that plant collect- ing mainly takes place relatively close to the home (Schulp et al., 2014). This is consistent with the image obtained from West Frisia, because many plants with high frequencies derive from local, settlement, or arable locations (Table 1).

Almost all of these plants are also known to have been collected based on the employed archaeological and ethnobotanical studies (Figure 1, bars with plus signs; Ertug, 2000, 2004; Behre, 2008; Łuczaj, 2010, 2012; Kalle and Sõukand, 2012). Off-site plant species actually form the broadest group, however, and even though they are known to be edible from the ethnobotanical online database, not all are recorded in the European ethnobotanical studies (Figure 1, bars without plus signs). Perhaps these plants represent a local preference or a local availability of these species. Alternatively, they could have been an essential food source in times of scarcity, which may no longer be experienced at similar scales in (northern) Europe today.

Another striking aspect of the data is the difference in frequency of plant remains. Some species are highly represented, although many appear to have low frequencies. This difference can be explained by evaluating the part of the plant consumed. The lower frequency plants almost all seem to fall in the category solely collected for its vegetative parts (Figure 1, green boxes; PFAF, 2015). The other species can be collected for both their seed/fruit and vegetative parts. Since vegetative plant parts are usually

Table 1. Overview of the ecogroups indicated by the edible plants from Bronze house ditches in West Frisia, The Netherlands ( $\mathrm{n}=174 \mathrm{samples).}$

\begin{tabular}{|c|c|c|c|}
\hline Ecogroup & Description & $\begin{array}{c}\text { Growing location } \\
\text { in relation } \\
\text { to the house }\end{array}$ & $\begin{array}{l}\text { Frequency of } \\
\text { wild edible } \\
\text { plants (n) }\end{array}$ \\
\hline ld & Trodden soils on dry, nutrient-rich soil & Local & 96 \\
\hline le & Brushwood on rarely trodden, nutrient-rich, non-humous or calcareous, dry soils & Settlement & 211 \\
\hline lf & Brushwood on rarely trodden, calcareous, non-humous, dry soil & Settlement & 2 \\
\hline $2 \mathrm{a}$ & Nutrient-rich locations with fluctuating water levels or otherwise greatly fluctuating environmental conditions & Settlement & 29 \\
\hline la & Arable fields on nutrient-rich, non-calcarious soil & Arable fields & 137 \\
\hline lc & Arable fields on medium nutrient-rich, poor calcareous soil & Arable fields & 12 \\
\hline \multicolumn{2}{|c|}{ Total (local, settlement, and arable fields) } & & 487 \\
\hline $2 b$ & Open, nutrient- (especially nitrogen-)rich, wet soil & Off-site & 8 \\
\hline $4 \mathrm{a}$ & Fresh to medium brackish, nutrient-rich waters & Off-site & 3 \\
\hline $4 \mathrm{c}$ & Fresh, medium to very nutrient-poor waters and their periodically drying banks & Off-site & 43 \\
\hline $4 \mathrm{~d}$ & Water way deposits, wet brushwood, and river-accompanying willow brush & Off-site & 4 \\
\hline $5 \mathrm{a}$ & Fertilised grassland on medium moist soil & Off-site & 114 \\
\hline $5 b$ & Medium fertilised grassland on medium moist soil & Off-site & 1 \\
\hline $6 \mathrm{~d}$ & Grasslands on dry, medium nutrient-poor, poor calcareous, acidic soils & Off-site & 6 \\
\hline $7 \mathrm{a}$ & Medium nutrient-rich, poor calcareous, acidic eutrophic peat bogs, and wet, humous dune valleys & Off-site & 2 \\
\hline $8 \mathrm{~b}$ & Borders on nutrient- (especially nitrogen-)rich, non-calcareous, humous, medium moist soil & Off-site & 13 \\
\hline $8 \mathrm{~d}$ & Brush on medium moist to dry, nutrient-rich soil & Off-site & 2 \\
\hline $9 \mathrm{a}$ & Forests on nutrient-rich, moist-to-wet soil & Off-site & 9 \\
\hline Total off-site & & & 205 \\
\hline
\end{tabular}


collected when the plant is not (yet) bearing seed, although this may sporadically occur, the chance of finding seeds from these plants is much lower than when plants are especially collected for their seeds. Therefore, plants collected for the latter purpose will always be over-represented in the archaeological record, because of all plant parts, seeds/fruits are preserved the best. Still, the number of West Frisian species potentially collected for vegetative parts is high, which is again comparable to the ethnobotanical studies.

\section{Taphonomical considerations}

The data comparison has shown that the potential for wild plant collecting, for seeds, and especially vegetative parts of plants, was high in West Frisia, particularly considering the narrow selection (house ditch charred remains) made on the total available data. It provides an insight into the gathering practices of Bronze Age people, and underlines the potential and importance of wild plants in the diet.

Based on Figure 1, it is clear that the actual spectrum and importance of wild plants used, especially for the vegetative parts, does not become apparent by only considering high frequencies of crops and wild plants (Brinkkemper, 2013). Low frequencies can be just as informative when considered properly. However, in order to evaluate the importance of wild plants represented by only low frequencies of seeds, the effect of taphonomy and the use of different plant parts need to be taken into account first. Since wild plant species collected for their vegetative parts are not well reflected in the archaeological record, it needs to be researched whether the low frequencies of wild plants in the Bronze Age can be explained by taphonomical processes, or by the (near) absence of gathering practices.

\section{Diet and nutrition}

Considering the quotes mentioned in the introduction, it seems that Bronze Age people could rely very well on their own produced food sources without the addition of wild resources. Nutritional studies were employed to evaluate whether such practices would indeed result in a healthy population.

The five most essential micronutrients for people consuming staple diets based on cereal grain are vitamin $\mathrm{A}, \mathrm{C}$, folate, iron, and zinc (WHO/FAO, 2002). Deficiencies (i.e. prolonged levels of less than $100 \%$ of the daily recommended nutrient intake) of these micronutrients can result in (fatal) ailments such as blindness, scurvy, anaemia, disrupted brain and muscle development, and stunted growth and higher susceptibility to infectious diseases, respectively (WHO/FAO, 2002). The Bronze Age farmer's diet was reconstructed assuming it normally consisted of cereals, beef, and raw milk (Piironen et al., 2008; Chatzav et al., 2010; Raw milk, 2015; USDA, 2015) in order to assess whether it provided high enough levels of the critical micronutrients. The assessment showed that this is indeed not the case and that without additional food sources, vitamin A and C levels are greatly insufficient (Figure 2). Diets consisting only of the domestic food sources produced by the settlement would result in a population either dying from scurvy (vitamin $\mathrm{C}$ deficiency) or suffering from blindness (vitamin A deficiency). Assuming neither was the case, people must have had access to vitamin A and C rich sources.

\section{Sources of vitamins $A$ and $C$}

Vitamins $\mathrm{A}$ and $\mathrm{C}$ may be acquired from animal sources, but there they are only available in low amounts and on a seasonal basis. Plants such as pulses or legumes, (leafy green) vegetables, and fruits however, have a high micronutrient density and are the preferred way of obtaining critical micronutrients (WHO/FAO, 2002), including vitamins A and C. The cultivation of legumes and vegetables is difficult to assess due to the fact that these plants are often harvested before setting seed. Evidence for their cultivation has been absent in West Frisia as well, despite the large dataset available. Therefore, wild plants must be con-

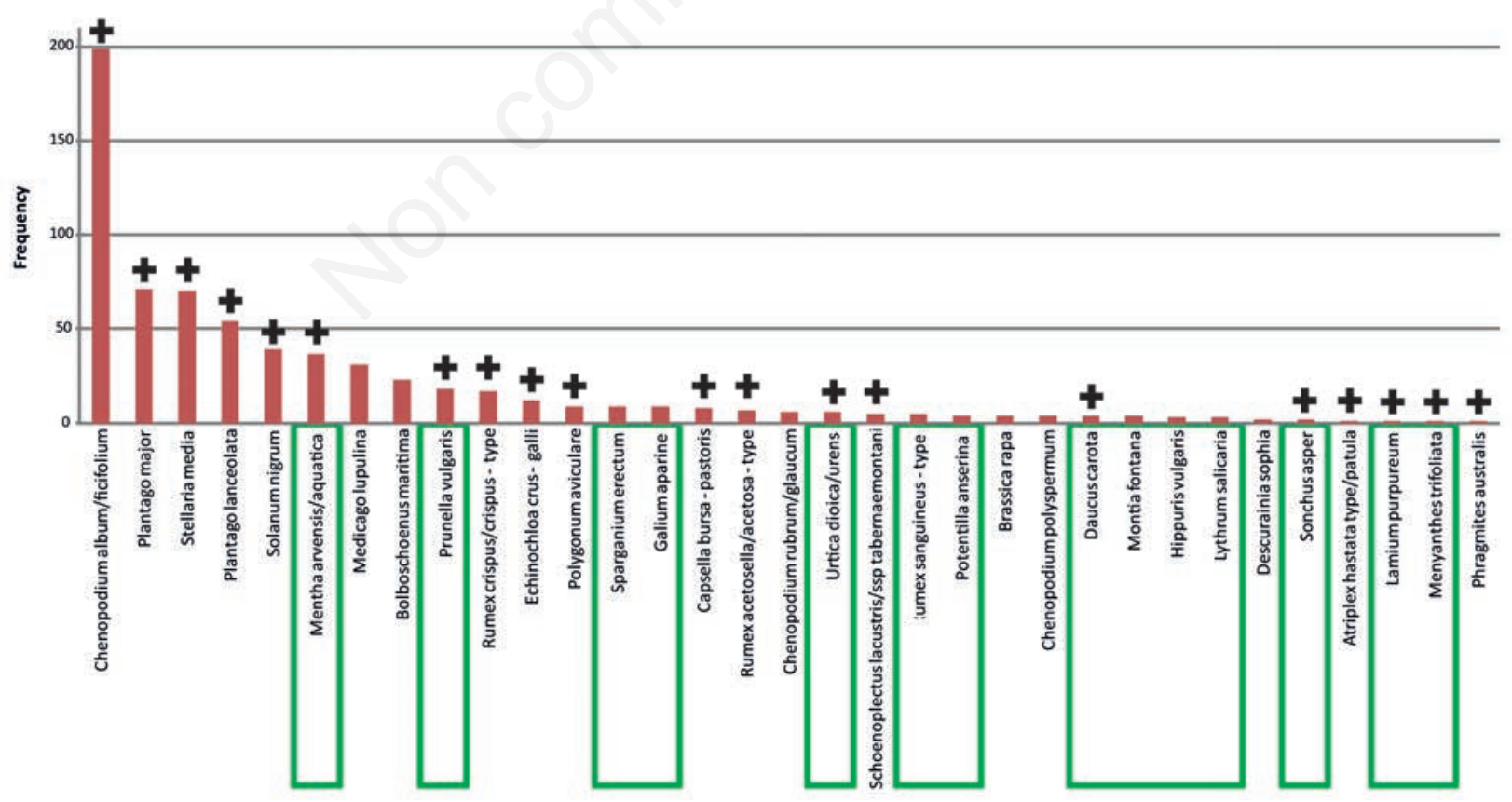

Figure 1. Frequencies of charred seeds of the edible plant species from Bronze Age house ditches, West Frisia, The Netherlands. Plus signs denote plants that are known to be collected based on archaeological and ethnobotanical studies. Green boxes denote plants collected for the consumption of their vegetative parts only. 
sidered, which are valuable resources of micronutrients as well.

In order to assess the vitamin $\mathrm{A}$ and $\mathrm{C}$ potential of wild plants in West Frisia, nutrient profiles of the wild plants from the data comparison were composed. The information on the critical micronutrients of these plants was obtained from research on Canadian indigenous people's wild plant use (Kuhnlein and
Turner, 1991). Although general micronutrient content may vary depending on the environmental conditions in which a plant grows, this mainly affects minerals, since these are absorbed from the surroundings. Vitamins on the other hand, are produced by the plant itself and are only influenced by available sunlight, location, and seasonality (Bernstein et al., 1945; USDA, 1948). Since Canada has a rela-

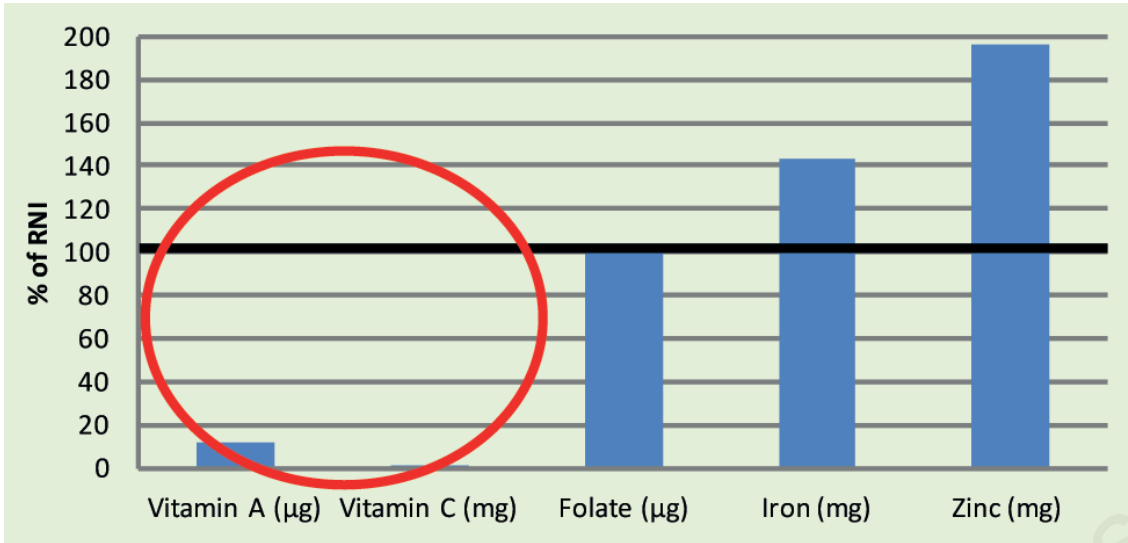

Figure 2. Overview of the diet of Bronze Age farmers based on cereals, red beef meat, and raw milk, without addition of wild resources. The bold black line indicates the recommended $100 \%$ daily nutrient intake (RNI) of the most important micronutrients. The red circle indicates the obvious lack of essential vitamins in this type of diet. tively similar latitude to north-western Europe, and therefore has mostly comparable sunlight hours and seasons, conditions which may affect vitamin content of wild plants are deemed largely comparable to West Frisia. In addition, many wild plant species are present in both areas.

A list of the vitamin content of the West Frisian wild plant species on which data was available was composed (Table 2). In this list, the energy obtainable from each species was compiled based on 100 grams of raw material, as well as the actual vitamin content of the plant species, its nutrient density (ND), and the amount of grams needed of each species to obtain the required $100 \%$ daily intake value (DV) of vitamin A and C.

\section{Vitamin contents of West Frisian wild plants}

Many of the West Frisian wild plants proved to be naturally rich in vitamins. The vitamin A and $\mathrm{C}$ content is highest in greens and leaves, although roots of Daucus carota also contain levels of vitamin C. Of the seeds, not much data was available on vitamin content, but they generally contain much less vitamins than young green parts of the plant. This would be an explanation for the fact that many presentday cultures collect plants mainly for their vegetative parts; the seeds of wild plants probably have comparable characteristics to the crops

Table 2. Energy and vitamin content based on 100 grams of raw material of the wild plant species uncovered from Bronze house ditches in West Frisia, The Netherlands. Also indicated are the nutrient density based on 100 grams of raw material, as well as the amount of grams needed of each species to obtain the required $100 \%$ daily intake value.

\begin{tabular}{|c|c|c|c|c|c|c|c|c|}
\hline Taxa & Part used & Energy (kcal) & mg & $\begin{array}{l}\text { Titamin } \\
\% \text { ND }\end{array}$ & $\begin{array}{l}\text { C } \\
100 \% \text { DV (g) }\end{array}$ & RE ( $\mu g)$ & $\begin{array}{r}\text { itamil } \\
\% \mathrm{ND}\end{array}$ & $\%$ DV (g) \\
\hline Brassica rapa & Greens & 22 & 130 & 433 & 42 & 990 & 198 & 116 \\
\hline Capsella bursa pastoris & Greens & 33 & 64 & 212 & 87 & 327 & 65 & 260 \\
\hline Chenopodium album cooked & Greens & 32 & 37 & 123 & 149 & 970 & 194 & 88 \\
\hline Chenopodium album raw & Greens & 34 & 98 & 328 & 56 & 1277 & 256 & 67 \\
\hline Montia fontana & Young greens & 31 & 34 & 115 & 160 & - & - & - \\
\hline Plantago major & Greens & - & 33 & 111 & 165 & - & - & - \\
\hline Polygonum aviculare & Greens & - & 78 & 260 & 71 & - & - & - \\
\hline Rumex acetosella & Greens & 43 & 34 & 112 & 164 & 560 & 112 & 152 \\
\hline Rumex crispus & Greens & 24 & 88 & 294 & 62 & 1014 & 203 & 84 \\
\hline Sonchus asper & Greens & 27 & 63 & 209 & 88 & - & - & - \\
\hline Urtica dioica & Greens & - & 90 & 299 & 61 & - & - & - \\
\hline Mentha sp. & Leaves & 39 & 64 & 213 & 86 & 1,334 & 267 & 64 \\
\hline Plantago major & Leaves & 61 & 8 & 27 & 688 & 252 & 50 & 337 \\
\hline Stellaria media & Leaves & - & 35 & 116 & 158 & 613 & 123 & 139 \\
\hline Urtica dioica & Leaves & 38 & 75 & 250 & 73 & 2248 & 450 & 38 \\
\hline Daucus carota & Roots & - & 24 & 80 & 229 & - & & \\
\hline Chenopodium album & Seeds & 414 & - & - & - & - & - & - \\
\hline Echinochloa crus-galli & Seeds & 417 & - & - & - & - & - & - \\
\hline Polygonum lapathifolium & Seeds & 425 & - & - & - & - & - & - \\
\hline
\end{tabular}

$\mathrm{ND}$, nutrient density; DV, daily intake value; RE, retinol equivalent. 
produced by farmers. From the plants of which greens and leaves are consumed, only $35-150 \mathrm{~g}$ of raw material needs to be eaten daily to meet vitamin $\mathrm{C}$ requirements (Figure 3 ). Especially greens of Brassica rapa, Chenopodium album, Urtica dioica, and Rumex crispus are very nutrient-dense. These species also grow at locations that are easily accessible to the farmers, since they can occur at the settlement or on arable fields. Plantago major leaves on the other hand, have relatively low vitamin $\mathrm{C}$ levels, so that more than $600 \mathrm{~g}$ needs to be consumed to meet demands.As said, vitamin C can also be obtained from the roots of Daucus caro$t a$, of which $200 \mathrm{~g}$ provides the daily-required levels. This plant could provide vitamin $\mathrm{C}$ during winter, but people would have to travel somewhat further from the settlement to obtain it because it grows on nitrogen-rich grasslands. Alternatively, people may have cultivated these plants in a vegetable garden, but the presence of such gardens in West Frisia remains undetermined.

Vitamin A is supplied by less species, but still 50-150 g of raw plant material is sufficient for most species to reach demands. However, the roots of Daucus carota, which are available during winter, do not contain vitamin A, which may form a problem during that time.

\section{Indications for general health and nutrient deficiencies in the Bronze Age}

Examples of general health level and possible micronutrient deficiencies in the Bronze Age were sought in the literature, to assess the probability of a deficient diet during this time period.

\section{General health}

The general health of past people can be identified by several types of marks present on the skeleton. These include porous bone in the top of the eye sockets (i.e. cribra orbitalia), growth arrest lines in femur or tibia (i.e. Harris lines), enamel formation arrest lines (i.e. enamel hypoplasia), dental caries, and overall stature.

Unfortunately, only a few indications for the general health of late prehistoric people exist in this area of Europe. A study in Sweden (Tornberg, 2013) includes remains from the Swedish Late Neolithic/Early Bronze Age (2300-1100 BC), and one other study was performed in Denmark (Bennike, 1985), encompassing only the Danish Late Neolithic (24001800 BC). Finally, in Northern Germany, Bronze Age/pre-Roman Iron Age cremation burials (500 BC-100 BC) have also given indications for general health (Hermanussen and Kühl, 2006). Although the cultural time periods researched in Sweden and Denmark differ from the Dutch periods, these times in prehistory are roughly comparable to the Early Bronze Age and Middle Bronze Age in the northern Netherlands. The German study falls just outside the Dutch Bronze Age, but will give indications for general health in the following period. Therefore, the data from these investigations into past health is used as a comparison for general health conditions during the Bronze Age in West Frisia.

Overall, thestudies seem to indicate a sufficient general health level, based on dental health, nutritional deficiency, stature (length of an individual), and healed trauma.

In the Netherlands, research towards stature and healed trauma on skeletons from the coastal area and from West Frisia was carried out. The results indicated that overall health in the Bronze Age was good (Smits and Maat, 1993; Veselka, 2015).

\section{Specific evidence for nutrient deficiencies}

Not all micronutrient deficiencies common in cereal based staple diets are reflected in skeletal material. Of the critical micronutrients, only vitamin $\mathrm{C}$ and iron deficiency can be recognised. Vitamin $\mathrm{C}$ deficiency can cause internal lesions and can provoke an effect on bones, but only when haemorrhaging takes place close to the skeleton. Iron deficiency causes anaemia, which in turn causes porous lesions to occur in the top of the eye-sockets. However, it must be kept in mind that anaemia can also be the result of the body's defence against pathogens, so it can signify infection rather than iron deficiency as well. Evidence for both conditions are found in the Early Bronze Age, although they seem rare (Mays, 2008; Mount, 2012).

It has become clear from the above examples, that Bronze Age people will surely have experienced times of nutrient scarcity in their diet, possibly annually. However, overall, they seem to have possessed a sufficient general health level without major deficiencies in vita$\min \mathrm{C}$ and iron in their diet. It can therefore be assumed that under normal circumstances, Bronze Age people were able to obtain enough vitamin $\mathrm{C}$, but not without the consumption of wild plants.

\section{Conclusions}

The use of wild plants will have been essential to the diet and well being of Bronze Age farmers. Relying solely on what can be produced by the settlement will have resulted in severe deficiencies, ultimately leading to death. Of course, people will not have been aware of micronutrient levels in their diets in the manner that is possible today. However, through a combination of cause-and-effect reasoning and thousands of years of knowledge of wild plant use in their ancestry, people will have realised the importance of a varied diet, which (still) included wild plants. Wild plants will have formed a constant vitamin-rich food source throughout the year, of which far more parts were gathered and consumed than just a few berries or nuts in autumn. Now that this practice can also be expected for the Bronze Age, more (specific) research towards the role of wild plants for subsistence should be undertaken.

Figure 3. Overview of the diet of Bronze Age farmers based on cereals, red beef meat, and raw milk, including $100 \mathrm{~g}$ of wild plant greens (average values of greens and leaves from Table 2). The bold black line indicates the recommended $100 \%$ daily nutrient intake (RNI) of the most important micronutrients. Folate is indicated in red, because the exact folate content measurements were not available for the researched wild plants, even though this micronutrient is present in wild plants. The actual amount of folate will thus be even higher than shown here. 


\section{References}

Behre K-H, 2008. Collected seeds and fruits from herbs as prehistoric food. Veg Hist Archaeobot 17:65-73.

Bennike P, 1985. Palaeopathology of Danish skeletons: a comparative study of demography, disease and injury. Akademisk Forlag, Copenhagen, Denmark.

Bernstein L, Hamner KC, Parks RQ, 1945. The influence of mineral nutrition, soil fertility, and climate on carotene and ascorbic acid content of turnip greens. Plant Physiol 20:540-72.

Brinkkemper 0, 2013. Environment and economy of Bronze Age settlements in two regions of the Netherlands. In: K-H Willroth (ed.) Siedlungen der älteren Bronzezeit. Beiträge zur Siedlungsarchäologie und Paläoökologie des zweiten vorchristlichen Jahrtausends in Südskandinavien, Norddeutschland und den Niederlanden. Wachholtz Verlag, Neumünster, Germany, pp 171-88.

Chatzav M, Peleg Z, Ozturk L, Yazici A, Fahima T, Cakmak I, Saranga Y, 2010. Genetic diversity for grain nutrients in wild emmer wheat: potential for wheat improvement. Ann Bot-London 105:1211-20.

Ertuğ F, 2000. An ethnobotanical study in central Anatolia (Turkey). Econ Bot 53:155-82.

Ertuğ F, 2004. Wild edible plants of the Bodrum area (Mugla, Turkey). Turk J Bot 28:16174.

Hermanussen H, Kühl I, 2006. Adolescent growth in Bronze Age and Iron Age people. Bull Schweiz Gesell Anthropol 12:19-23.

Kalle R, Sõukand R, 2012. Historical ethnobotanical review of wild edible plants of
Estonia (1770s-1960s). Acta Soc Bot Pol 81:271-81.

Kuhnlein HV, Turner NJ, 1991. Traditional plant foods of Canadian indigenous peoples: nutrition, botany, and use. Gordon and Breach, Philadelphia, PA, USA.

Louwe Kooijmans LP, 1993. Wetland exploitation and upland relations of prehistoric communities in the Netherlands. In: J Gardiner (ed.). Flatlands and wetlands: current themes in East Anglian archaeology. East Anglian Archaeology, East Dereham, UK, pp 71-116.

Łuczaj $Ł$, 2010. Changes in the utilization of wild green vegetables in Poland since the 19th century: a comparison of four ethnobotanical surveys. J Ethnopharmacol 128:395-404.

Łuczaj $Ł$, 2012. Ethnobotanical review of wild edible plants of Slovakia. Acta Soc Bot Pol 81:245-55.

Mays S, 2008. A likely case of scurvy from Early Bronze Age Britain. Int J Osteoarchaeol 18:178-87.

Mount C, 2012. Was there malaria in prehistoric Ireland? Available from: http://charles-mount.ie/wp/?p=883

Murdock GP, 1981. Atlas of world cultures. University of Pittsburgh Press, Pittsburgh, PA, USA.

PFAF, 2015. Plants For A Future: online ethnobotanical database, 2015. Available from: http://pfaf.org/user/plantsearch.aspx

Piironen V, Edelmann M, Kariluoto S, Bedo Z, 2008. Folate in wheat genotypes in the HEALTHGRAIN diversity screen. J Agr Food Chem 56:9726-31.

Raw milk, 2015. What's in raw milk? Available from: http://www.raw-milk-facts.com/what _is_in_raw_milk.html
Schulp CJE, Thuiller W, Verburg PH, 2014. Wild food in Europe: a synthesis of knowledge and data of terrestrial wild food as an ecosystem service. Ecol Econ 105:292-305.

Smits E, Maat G, 1993. An Early/Middle Bronze Age common grave at Wassenaar, the Netherlands. The physical anthropological results. Available from: https://openaccess.leidenuniv.nl/handle/1887/27908

Tamis WLM, Van der Meijden R, Runhaar J, Bekker RM, Ozinga WA, Odé B, Hoste I, 2004. Standaardlijst van de Nederlandse flora 2003. Gorteria 30:101.

Tornberg A, 2013. Diet, health and agriculture: the Late Neolithic-Early Bronze Age example of Abbekås, Southern Sweden. Lund Arch Rev 19:7-18.

USDA, 1948. Factors affecting the nutritive value of foods: studies at the U.S. plant, soil, and nutrition laboratory. US Department of Agriculture, Washington, DC, USA.

USDA, 2015. National nutrient database for standard reference. Available from: http://ndb.nal.usda.gov

van Amerongen YF, in press. Wild West Frisia: the role of domestic and wild resource exploitation in Bronze Age subsistence. PhD thesis. Sidestone Press, Leiden, the Netherlands.

Veselka B, 2015. Menselijk skeletmateriaal uit Zwaagdijk-Wervershoof. Stichting LAB, Leiden, The Netherlands.

WHO/FAO, 2002. Human vitamin and mineral requirements: report of a joint FAO/WHO expert consultation, Bangkok, Thailand. Food and Agriculture Organization of the United Nations, Rome, Italy. 